\title{
Evaluation of masseter muscles in relation to treatment with removable bite-blocks in dolichofacial growing subjects: A...
}

Article in American Journal of Orthodontics and Dentofacial Orthopedics · May 2017

DOI: 10.1016/j.ajodo.2016.10.035

CITATIONS

0

6 authors, including:

\section{Roberta Lione}

University of Rome Tor Vergata

37 PUBLICATIONS 225 CITATIONS

SEE PROFILE

\section{Paola Cozza}

University of Rome Tor Vergata, Rome, Italy

199 PUBLICATIONS 1,580 CITATIONS

SEE PROFILE
READS

55
Stavros Kiliaridis

University of Geneva

207 PUBLICATIONS 4,916 CITATIONS

SEE PROFILE

Some of the authors of this publication are also working on these related projects: 


\title{
Evaluation of masseter muscles in relation to treatment with removable bite-blocks in dolichofacial growing subjects: A prospective controlled study
}

\author{
Roberta Lione, ${ }^{a}$ Stavros Kiliaridis, ${ }^{b}$ Andrea Noviello, ${ }^{c}$ Lorenzo Franchi, ${ }^{d}$ Gregory S. Antonarakis, ${ }^{b}$ \\ and Paola Cozza \\ Rome and Florence, Italy, Tirana, Albania, Geneva, Switzerland, and Ann Arbor, Mich
}

\begin{abstract}
Introduction: The aim of this prospective study was to evaluate the effects of posterior bite-blocks on masseter muscles and on facial growth in prepubertal dolichofacial subjects. Methods: The treatment group comprised 21 consecutive prepubertal dolichofacial patients treated with rapid maxillary expansion followed by mandibular removable bite-blocks. Lateral cephalograms and ultrasonographic scans of the masseter muscles were made before (T1) and after (T2) treatment with bite-blocks. The treatment group was compared with a control group of 21 subjects matched for sex, age, and skeletal vertical pattern. An independent samples $t$ test was used to compare the T1 to T2 changes in ultrasonographic scan measurements between the treatment group and the control group, and the T1 to T2 cephalometric changes in the treatment group. Regression analysis was performed to investigate associations between masseter muscle thickness and cephalometric treatment outcomes. Results: Masseter muscle thickness showed a statistically significant decrease $(-0.7 \mathrm{~mm})$ in the treatment group compared with an increase $(+0.6 \mathrm{~mm})$ in the control group. A significant anterior rotation of the mandibular plane was observed in the treatment group as well as significant increases in overbite $(1.8 \mathrm{~mm})$ and total posterior facial height $(1.5 \mathrm{~mm})$. No significant associations were found between masseter muscle thickness and treatment outcomes apart from a tendency for overbite to increase more in subjects with thicker muscles. Conclusions: Treatment with removable bite-blocks produced a decrease in masseter muscle thickness and a reduction in vertical facial dimensions due to upward and forward rotation of the mandible. No significant correlation was found between the pretreatment masseter muscle thickness and the T1 to T2 cephalometric changes in the treatment group. (Am J Orthod Dentofacial Orthop 2017;151:1058-64)
\end{abstract}

\footnotetext{
Tr p $\mathrm{n}$ patients with high-angle mandibular patterns, the treatment strategy is based on the inhibition of vertical development or the intrusion of buccal dentoalveolar structures with various kinds of bite-blocks (BBs) or extraoral appliances. The purpose is to induce upward

${ }^{a}$ Department of Clinical Sciences and Translational Medicine, University of Rome “Tor Vergata," Rome, Italy; Department of Dentistry, Università Nostra Signora del Buon Consiglio, Tirana, Albania.

${ }^{\mathrm{b}}$ Department of Orthodontics, University of Geneva, Geneva, Switzerland.

cDepartment of Clinical Sciences and Translational Medicine, University of Rome "Tor Vergata," Rome, Italy.

${ }^{\mathrm{d}}$ Department of Surgery and Translational Medicine, University of Florence, Florence, Italy; Thomas M. Graber Visiting Scholar, Department of Orthodontics and Pediatric Dentistry, School of Dentistry, University of Michigan, Ann Arbor, Mich. All authors have completed and submitted the ICMJE Form for Disclosure of Potential Conflicts of Interest, and none were reported.

Address correspondence to: Roberta Lione, Department of Clinical Sciences and Translational Medicine, University of Rome "Tor Vergata”, Viale Oxford, 81, Rome 00133, Italy; e-mail, robertalione@yahoo.it.

Submitted, April 2016; revised and accepted, October 2016

$0889-5406 / \$ 36.00$

(C) 2017 by the American Association of Orthodontists. All rights reserved.

http://dx.doi.org/10.1016/j.ajodo.2016.10.035
}

and forward rotation of the mandible to express a more horizontal growth direction, rather than vertical. ${ }^{1} \mathrm{~A}$ functional treatment approach is indicated before the completion of growth to guide the vertical forces developed during mastication against the posterior teeth and the alveolar process. ${ }^{2}$ If muscle strength can affect facial form, increasing the activity of the muscles of mastication with the help of BBs could positively affect the skeletal pattern of long-faced children. ${ }^{3,4}$

In this respect, masseter muscle thickness, an indicator of the functional capacity of the masticatory apparatus, may be an important functional factor in the treatment of vertical skeletal discrepancies with functional appliances. ${ }^{5}$

A strong relationship between muscle activity, mandibular form, and craniofacial growth pattern has been demonstrated in several studies. ${ }^{6-8}$ Clinical investigations, mostly performed in adults, have shown that thicker masseter muscles and those with increased 
muscle activity are associated with smaller gonial angles and shorter faces. ${ }^{9-12}$ Eckardt and Harzer ${ }^{13}$ observed that masseter muscle volume has a negative correlation with the steepness of the mandibular plane and the size of the gonial angle, and a positive correlation with posterior face height and ramus height. They concluded that an increased volume of the masseter muscles in adults was related to an anterior growth direction of the mandible. ${ }^{13}$ In addition to the influence of the masticatory muscles on facial morphology, Antonarakis and Kiliaridis ${ }^{14}$ in a prospective study demonstrated that the functional capacity of the masticatory muscles can also influence treatment outcomes during functional appliance therapy in Class 11 Division 1 growing children. Therefore, one can hypothesize that differences in masticatory muscle capacity may influence treatment outcome with posterior BB because of their role in controlling the vertical dimension.

Little is known, however, about the association between the characteristics of the masticatory muscles and treatment effects when using posterior BBs and, inversely, the effects of BB treatment on the masticatory musculature. Limited knowledge exists in this area, and most studies have been carried out using electromyography, which may not be the most suitable method to investigate the true activity of the muscles under investigation. ${ }^{15,16}$

A reliable method available for the evaluation of masticatory muscle capacity is ultrasonography, by measuring the cross-sectional thickness of the muscles. The superficial position of the masseter muscles allows for easy access for thickness measurements with this method. ${ }^{17}$

The hypothesis underlying this investigation is that the insertion of a removable posterior BB influences the morphology of the mandible during growth, and that this influence depends on the thickness of the masticatory muscles. Therefore, the aim of this study was to evaluate the effects of treatment with removable posterior BBs on masseter muscle thickness and on dentoskeletal structures in dolichofacial growing subjects.

\section{MATERIAL AND METHODS}

The sample of this prospective study included a treatment group (TG) and a control group (CG), each comprising 21 subjects. A sample of 21 subjects was chosen after a sample size calculation to detect at least a difference of $0.8 \mathrm{~mm}$ in masseter muscle thickness between the 2 groups, with a standard deviation of $0.9 \mathrm{~mm},{ }^{14}$ an alpha value of 0.05 , and a power of 0.8 , using specific software (SigmaStat version 3.5; Systat Software, Point Richmond, Calif).

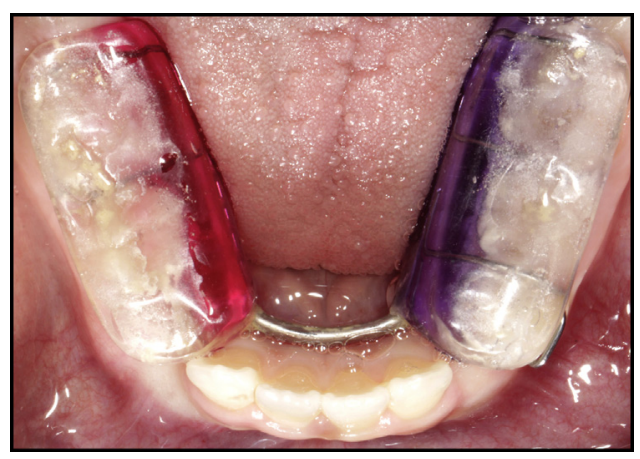

Fig 1. Mandibular removable posterior BB.

A TG of 21 consecutive patients ( 12 girls, 9 boys) who sought orthodontic treatment at the Department of Orthodontics at the University of Rome "Tor Vergata," in ltaly with a mean age of $9.9 \pm 1.4$ years (range, 8.511.1 years) was selected according to the following inclusion criteria: prepubertal stage of development (CS1-CS3 in cervical vertebral maturation), ${ }^{18}$ mixed dentition, negative posterior transverse interarch discrepancy, ${ }^{19}$ and a skeletal hyperdivergent pattern (sella nasion to mandibular plane angle, $\geq 35^{\circ}$ ). ${ }^{20}$ Exclusion criteria included absence of the first molars, skeletal asymmetries, temporomandibular joint diseases, facial clefts or congenital craniofacial anomalies, previous facial trauma, and previous orthodontic treatment.

This project was approved by the ethical committee at the University of Rome "Tor Vergata" (protocol number 79/15), and informed consent was obtained from parents.

Each patient underwent a standardized protocol with rapid maxillary expansion in the form of a butterfly palatal expander ${ }^{21}$ cemented through bands on the maxillary permanent first molars, followed by a mandibular removable BB (Fig 1).22 The expansion screw was activated 2 turns per day ( $0.25 \mathrm{~mm}$ per turn) until the desired expansion was achieved. The expander was kept in place as a passive retainer for 6 months. At the end of the retention period, the expander was removed, and a removable mandibular BB was applied for 12 months to control the vertical dimension. The thickness of the posterior BB was $5 \mathrm{~mm}$. Patients were instructed to wear the appliance full time except for meals and for toothbrushing. As in studies involving any removable device, compliance with the instructions of the orthodontist and staff varied among patients. Therefore, compliance was appraised with a 3-point Likert scale (poor, moderate, good). ${ }^{23}$ Poor compliance was reported when the patient wore the BB at night only; moderate compliance occurred when the patient wore 
the BB at night and during the day at home, and good compliance was when the patient wore the BB full time as suggested by the clinician. For the TG, lateral cephalograms and ultrasonographic scans of the masseter muscles were performed when the expander was removed at the end of 6-month retention period before applying the $\mathrm{BB}$ (T1) and after 1 year of treatment with the BB (T2).

The CG consisted of 21 growing subjects (12 girls, 9 boys) matched for sex, age, (9.6 \pm 1.6 years), and skeletal divergence without an immediate need for orthodontic treatment. The CG was followed without treatment for 1 year and had only an initial lateral cephalogram, but ultrasonographic recordings before (T1) and after the 1-year interval (T2).

For all subjects, masseter muscle thickness was measured by means of an ultrasonographic scan. The scans were performed by a trained and calibrated examiner (A.N.) using a real-time scanner with a linear array transducer. All ultrasound measurements were made in a darkened room with the subjects seated upright with no head support. The scans were performed bilaterally during muscle contraction obtained by asking the participants to clench maximally in the intercuspal position. According to the technique of Kiliaridis and Kalebo ${ }^{17}$ and modified by Raadsheer et al, ${ }^{24}$ the probe was oriented perpendicular to the anterior border of the muscle and perpendicular to the surface of the underlying ramus of the mandible. The masseter was scanned on a line connecting the lip angle and the tragus to register the scan planes at right angles to the long axis of the muscle and to prevent bias in obtaining the real size of the masseter muscle. Light pressure was applied to prevent compression of the soft tissues and muscles, thus avoiding erroneous measurements. All registrations were repeated twice, and the final values were obtained from the mean of the repeated measurements.

All lateral cephalograms were hand traced at 1 sitting, and landmark identification was performed by 1 investigator (R.L.). A customized digitization regimen (Viewbox, version 3.0; dHAL Software, Kifissia, Greece) was created and used for the cephalometric evaluation. Lateral cephalograms of the TG and CG were standardized with regard to magnification by setting this at $0 \%$.

The cephalometric reference points, lines, and angles used in the analysis are shown in Figure 2.

\section{Statistical analysis}

To determine the reliability of the method, ultrasonographic measurements on half of the subjects were performed by a trained examiner (A.N.) and repeated after an interval of approximately 2 weeks. Twenty

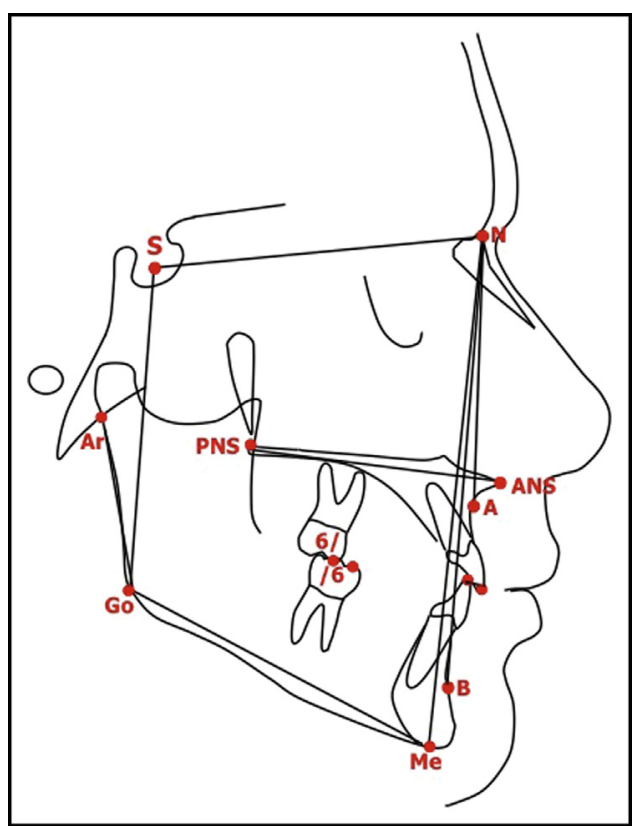

Fig 2. Cephalometric points, lines, and angles used in analysis: SNA; SNB; ANB; SN to palatal plane (ANS$\mathrm{PNS}$ ); $\mathrm{SN}$ to mandibular plane (Me-Go); palatal plane (ANS-PNS) to mandibular plane (Me-Go); gonial angle (Ar-Go-Me); overjet; overbite; maxillary first molar (6/) to palatal plane (ANS-PNS); mandibular first molar (/6) to mandibular plane (Me-Go); total posterior facial height (S-Go); total anterior facial height (N-Me).

radiographs chosen at random were traced and digitized by the same investigator on 2 separate occasions at least 1 month apart. A paired $t$ test was used to compare the 2 measurements (systematic error). The magnitude of the random error was calculated by using the method of moments estimator. ${ }^{25}$

Exploratory statistics showed that all cephalometric and ultrasonographic variables were normally distributed (Kolmogorov-Smirnov test) with equality of variances (Levene test). An independent sample $t$ test was used to compare the T1 to T2 changes in ultrasonographic measurements between the TG and the CG. Descriptive statistics (means and standard deviations), 95\% confidence intervals, and statistical comparisons using paired $t$ tests were calculated for the T1 to T2 cephalometric changes in the TG.

Linear regression analysis was carried out to investigate whether the initial masseter muscle thickness could be considered as a predictor (independent variable) for treatment outcomes (T1-T2 cephalometric changes in the TG, dependent variables). All linear regressions were considered significant at $P<0.05$.

All statistical computations were performed with SPSS software (version 12; SPSS, Chicago, 111). 
Table I. Demographics of the 2 groups, descriptive statistics, and statistical comparisons at T1 (starting forms) with independent sample $t$ test

\begin{tabular}{|c|c|c|c|c|c|c|}
\hline \multirow[b]{2}{*}{ Variable } & \multicolumn{2}{|c|}{$\begin{array}{c}\text { Treated group } \\
(n=21 ; 12 \mathrm{~F}, 9 \mathrm{M})\end{array}$} & \multicolumn{2}{|c|}{$\begin{array}{c}\text { Control group } \\
(n=21 ; 12 F, 9 M)\end{array}$} & \multicolumn{2}{|c|}{ Statistical comparison } \\
\hline & Mean & $S D$ & Mean & $S D$ & Difference & $\mathrm{P}$ value \\
\hline Age at $\mathrm{T} 1(\mathrm{y})$ & 9.9 & 1.4 & 9.6 & 1.6 & -0.3 & NS \\
\hline Age at T2 (y) & 10.9 & 1.4 & 10.5 & 1.9 & 0.4 & NS \\
\hline $\mathrm{SN}^{\wedge}$ palatal plane $\left(^{\circ}\right)$ & 9.5 & 2.6 & 8.5 & 2.4 & 1.0 & NS \\
\hline $\mathrm{SN}^{\wedge}$ mandibular plane $\left(^{\circ}\right)$ & 43.5 & 5.5 & 40.6 & 3.3 & 2.9 & NS \\
\hline Palatal plane ${ }^{\wedge}$ mandibular plane $\left({ }^{\circ}\right)$ & 34.0 & 6.0 & 32.1 & 3.3 & 1.9 & NS \\
\hline
\end{tabular}

$F$, Female; $M$, male; $N S$, not significant.

Table Il. Descriptive statistics and statistical comparisons of masseter muscle thickness at T1 and T2 in both groups with independent sample $t$ test

\begin{tabular}{|c|c|c|c|c|c|c|c|}
\hline \multirow{2}{*}{$\begin{array}{l}\text { Masseter muscle } \\
\text { thickness }(\mathrm{mm})\end{array}$} & \multicolumn{2}{|c|}{ Treated group $(n=21 ; 12 F, 9 M)$} & \multicolumn{2}{|c|}{ Control group $(n=21 ; 12 \mathrm{~F}, 9 \mathrm{M})$} & \multicolumn{3}{|c|}{ Statistical comparison } \\
\hline & Mean & $S D$ & Mean & $S D$ & Difference & $95 \% C I$ & $\mathrm{P}$ value \\
\hline $\mathrm{T} 1$ & 9.6 & 0.7 & 10.3 & 1.7 & -0.7 & $-1.5,0.1$ & NS \\
\hline T2 & 8.9 & 0.7 & 10.9 & 1.7 & -2.0 & $-2.8,-1.2$ & * \\
\hline T1-T2 & -0.7 & 0.3 & 0.6 & 0.3 & -1.3 & $-1.5,-1.1$ & * \\
\hline
\end{tabular}

$F$, Female; $M$, male; $N S$, not significant.

${ }^{*} P<0.001$.

\section{RESULTS}

No systematic error was found between the repeated ultrasonographic measurements or between the repeated cephalometric values. For the masseter muscle thickness, the random error was $0.2 \mathrm{~mm}$. For the cephalometric variables, the random error varied from $0.18^{\circ}$ (SNA angle) to $0.35^{\circ}$ (gonial angle) for angular measurements, and from $0.13 \mathrm{~mm}$ (S-Go) to $0.28 \mathrm{~mm}$ (overbite) for linear measurements. No significant between-group differences were found at $\mathrm{T} 1$ for the skeletal vertical cephalometric variables and for masseter muscle thickness (Tables 1 and 11).

Masseter muscle thickness showed a statistically significant decrease of $0.7 \mathrm{~mm}( \pm 0.3 \mathrm{~mm})$ for the TG compared with an increase of $0.6 \mathrm{~mm}( \pm 0.3 \mathrm{~mm})$ for the CG (Table 11; Fig 3). Therefore, the difference between the 2 groups was $1.3 \mathrm{~mm}$.

After 1 year of treatment with BBs, significant anterior rotations of the mandibular plane were observed in the TG (sella nasion to mandibular plane angle, $1.5^{\circ}$; palatal plane to mandibular plane angle, $1.6^{\circ}$; gonial angle, $1.7^{\circ}$ ). Significant increases of $1.8 \mathrm{~mm}$ of overbite and total posterior facial height of $1.5 \mathrm{~mm}$ were also found in the TG (Table 111).

No significant correlation was found between the pretreatment masseter muscle thickness and the T2 to $\mathrm{T} 1$ cephalometric changes in the TG (Table IV).

The analysis of compliance of the treated subjects during therapy (use of $\mathrm{BB}$ ) showed that none had poor

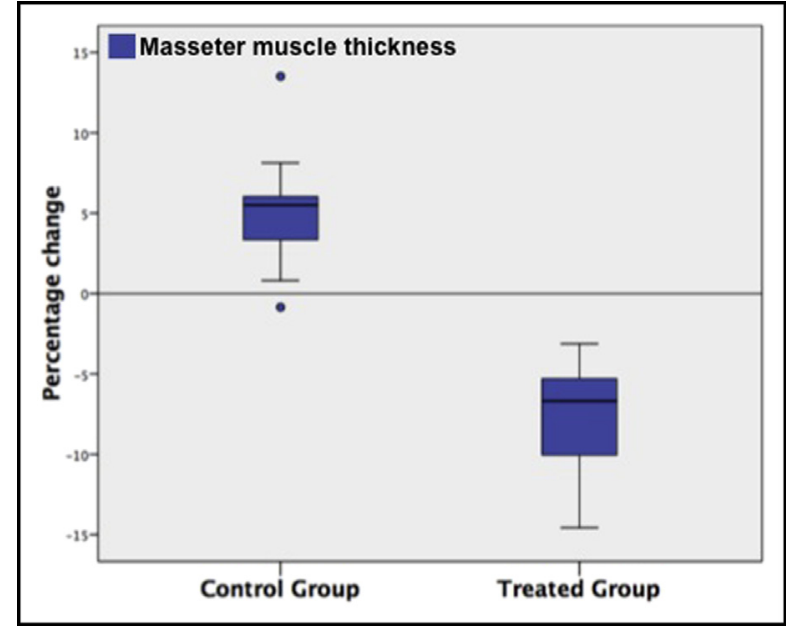

Fig 3. Box plots showing changes in masseter muscle thickness (expressed as percentages of change) for the $\mathrm{CG}$ and TG. The lower border of the box represents the lower quartile, the upper border the upper quartile, and the line in the box represents the median. Whiskers represent upper and lower limits, and the points the outliers. The horizontal line at $0 \%$ represents a line below which the measurement showed a decrease, and above which the measurement showed an increase.

cooperation; 5 had moderate cooperation, and the remaining 16 patients had good compliance. As a result, therefore, cooperation was good in $76.2 \%$ of the patients. 
Table III. Descriptive statistics and statistical comparisons of the T1-T2 changes with paired $t$ test

\begin{tabular}{|c|c|c|c|c|c|c|c|}
\hline \multirow[b]{2}{*}{ Measurement } & \multicolumn{2}{|c|}{$\stackrel{T 1}{\text { Treated group }(n=21)}$} & \multicolumn{2}{|c|}{$\begin{array}{c}T 2 \\
\text { Treated group }(n=21)\end{array}$} & \multicolumn{3}{|c|}{ Statistical comparison } \\
\hline & Mean & $S D$ & Mean & $S D$ & Difference & $95 \% C I$ & $\mathrm{P}$ value \\
\hline SNA $\left({ }^{\circ}\right)$ & 78.7 & 3.6 & 78.5 & 3.7 & -0.2 & $-0.5,0.8$ & NS \\
\hline SNB $\left(^{\circ}\right)$ & 74.6 & 3.8 & 74.7 & 4.0 & -0.1 & $-0.7,0.5$ & NS \\
\hline ANB $\left(^{\circ}\right)$ & 4.1 & 1.9 & 3.8 & 2.1 & -0.3 & $-0.5,0.9$ & NS \\
\hline $\mathrm{SN}^{\wedge}$ palatal plane $\left(^{\circ}\right)$ & 9.5 & 2.6 & 9.7 & 2.8 & 0.2 & $-1.1,0.9$ & NS \\
\hline $\mathrm{SN}^{\wedge}$ mandibular plane $\left({ }^{\circ}\right)$ & 43.5 & 5.5 & 42.0 & 5.8 & -1.5 & $0.6,2.4$ & 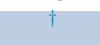 \\
\hline Palatal plane ${ }^{\wedge}$ mandibular plane $\left(^{\circ}\right)$ & 34.0 & 6.0 & 32.4 & 6.4 & -1.6 & $0.4,2.9$ & * \\
\hline $\operatorname{ArGoMe~}\left(^{\circ}\right)$ & 134.1 & 3.9 & 132.4 & 5.5 & -1.7 & $0.2,3.1$ & * \\
\hline Overjet (mm) & 4.3 & 2.3 & 3.6 & 1.9 & -0.7 & $-1.7,1.5$ & NS \\
\hline Overbite (mm) & -0.8 & 2.6 & 1.0 & 1.7 & 1.8 & $-2.6,-1.1$ & 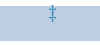 \\
\hline Maxillary 6-palatal plane (mm) & 17.6 & 1.7 & 17.5 & 2.2 & -0.1 & $-0.6,0.8$ & NS \\
\hline Mandibular 6-mandibular plane $(\mathrm{mm})$ & 25.0 & 1.5 & 25.5 & 1.8 & 0.5 & $-1.1,0.0$ & NS \\
\hline S-Go (mm) & 63.1 & 4.3 & 64.6 & 4.6 & 1.5 & $-2.7,0.2$ & * \\
\hline N-Me (mm) & 108.3 & 7.5 & 108.9 & 7.3 & 0.6 & $-2.2,1.1$ & NS \\
\hline
\end{tabular}

Table IV. Linear regression analysis between pretreatment masticatory muscle thickness and treatment changes

\begin{tabular}{|c|c|c|c|c|}
\hline Independent variable (at T1) & Dependent variable (T1-T2) & $\mathrm{R}$ value & t statistic & $\mathrm{P}$ value \\
\hline Masseter muscle thickness & SNA $\left({ }^{\circ}\right)$ & 0.013 & -0.055 & 0.957 \\
\hline Masseter muscle thickness & SNB $\left(^{\circ}\right)$ & 0.096 & -0.421 & 0.678 \\
\hline Masseter muscle thickness & ANB $\left(^{\circ}\right)$ & 0.069 & 0.301 & 0.767 \\
\hline Masseter muscle thickness & $\mathrm{SN}^{\wedge}$ palatal plane $\left({ }^{\circ}\right)$ & 0.264 & -0.264 & 0.247 \\
\hline Masseter muscle thickness & $\mathrm{SN}^{\wedge}$ mandibular plane $\left(^{\circ}\right)$ & 0.002 & 0.002 & 0.992 \\
\hline Masseter muscle thickness & Palatal plane ${ }^{\wedge}$ mandibular plane $\left({ }^{\circ}\right)$ & 0.211 & 0.942 & 0.358 \\
\hline Masseter muscle thickness & $\operatorname{ArGoMe}\left({ }^{\circ}\right)$ & 0.111 & 0.486 & 0.632 \\
\hline Masseter muscle thickness & Overjet (mm) & 0.334 & 1.544 & 0.139 \\
\hline Masseter muscle thickness & Overbite (mm) & 0.357 & 1.668 & 0.112 \\
\hline Masseter muscle thickness & Maxillary 6-palatal plane (mm) & 0.018 & 0.076 & 0.940 \\
\hline Masseter muscle thickness & Mandibular 6-mandibular plane (mm) & 0.148 & 0.651 & 0.523 \\
\hline Masseter muscle thickness & S-Go (mm) & 0.082 & 0.361 & 0.722 \\
\hline Masseter muscle thickness & $\mathrm{N}-\mathrm{Me}(\mathrm{mm})$ & 0.001 & 0.003 & 0.997 \\
\hline
\end{tabular}

\section{DISCUSSION}

The aim of this investigation was to analyze the changes in thickness of the masseter muscle and the dentoskeletal modifications after treatment with removable BBs in growing subjects with a high-angle mandibular pattern. Apart from the masseter muscle, other masticatory muscles may be influenced by functional appliance treatment, such as the lateral pterygoid, medial pterygoid, digastric, and temporalis that come into play during mandibular grinding forces. ${ }^{26}$ In our study, masseter muscle thickness was investigated as representing masticatory muscle dimensions. ${ }^{27}$

Ultrasonography was used to measure the thickness of the masseter muscle in vivo, giving quantitative information about the functional capacity of the muscle. ${ }^{28}$ Ultrasonography provides reproducible information on jaw muscle function, allowing for assessment of large- scale longitudinal changes in masticatory muscle thickness during growth and orthodontic treatment. ${ }^{29}$

The posterior BB was applied in growing children at the end of the 6-month retention period when the expander was removed to control the vertical dimension and to test its effects on masticatory muscles. All records were taken after treatment with rapid maxillary expansion so as not to include in the analysis the effects of orthopedic expansion on dentoskeletal structures. However, expansion may have also influenced the masseter muscle thickness; thus the thickness measured at T1 may have been different from that measured before treatment. Another limitation of this investigation was the lack of a control group that would allow discrimination of treatment changes from natural growth. The main difficulties with an untreated control group are that the children must be longitudinally 
followed with additional radiographs that cannot be justified and the ethical concern of not treating subjects who might need orthodontic therapy. To overcome those problems, a historical control group might be used. However, the use of historical controls seems to be associated with systematic bias that can be attributed to an imbalance in distribution of patient characteristics, selection bias, and temporal bias. ${ }^{30}$

Removable posterior BBs are functional appliances, hinging the mandible open by producing and maintaining pressure on the neuromuscular system supporting the mandible. ${ }^{2,31}$ The prime objectives of functional appliances are to take advantage of muscle forces and to transmit them to the dentoalveolar structures in accordance with desired changes. ${ }^{32}$

In our study, the hypothesis of training the masticatory muscles by inserting a passive BB was rejected. The masseter thickness showed a significant decrease of $0.7 \mathrm{~mm}$ during contraction in treated patients compared with untreated subjects, who showed an increase of $0.6 \mathrm{~mm}$ (Table 1l, Fig 3). The increase in masseter muscle thickness in the CG can be associated with the general increase in muscle force in growing children that has been previously demonstrated by several longitudinal studies. $^{33,34}$

As proposed by Antonarakis and Kiliaridis, ${ }^{14}$ functional appliances may lead to mild atrophy of the masticatory muscles and to decreased functional activity due to occlusal instability. Another possible hypothesis explaining the reduction in masseter muscle thickness may be the stretching of the muscle with a consequent adaptation in the muscle to compensate for the increased length. These findings agree with those of Kiliaridis et $\mathrm{al}^{28}$ and Freeland, ${ }^{35}$ who detected a reduction in muscle activity in growing patients undergoing functional therapy for mandibular advancement.

Nevertheless, in our study, treatment with posterior BBs was able to reduce the vertical dimension in subjects with a high mandibular angle. Several studies have reported that in addition to the inhibitory effect on the height of the dentoalveolar process, BBs produce an increase in the vertical growth of the condyle and a consequent reduced steepness of the mandibular and occlusal planes. ${ }^{1,5,36}$

In this investigation, treatment with BBs induced a significant anterior rotation of the mandibular plane (sella nasion to mandibular plane angle, $1.5^{\circ}$; palatal plane to mandibular plane angle. 1.6 ; gonial angle, $1.7^{\circ}$ ) that was associated with significant increases of $1.8 \mathrm{~mm}$ in overbite and of $1.5 \mathrm{~mm}$ in total posterior facial height. These findings are similar to those reported in previous studies that analyzed the dentoskeletal effects of passive and active BBs in subjects with the same mean age. ${ }^{2,3,36}$ ln contrast to these investigations, we did not find a reduction in posterior dentoalveolar heights. This difference is probably due to the fact that the patients of our TG had smaller maxillary and mandibular dentoalveolar heights associated with a less severe anterior open bite. If the cephalometric changes seen in the TG are compared with an untreated control group of similar ages, it can be seen that untreated patients have nonsignificant vertical changes (a mean decrease in $0.3^{\circ}$ of the sella nasion to mandibular plane angle). ${ }^{37}$ By extrapolation, one can say that the anterior mandibular rotation seen in the TG was in response to the treatment and not to normal growth.

No statistically significant associations were found between masseter muscle thickness and treatment effects after treatment with BBs. This may have been due to limitations related to the sample size, since the study was powered to detect differences in masseter muscle thickness between groups but not correlations within the TG. However, one can see a tendency for a greater reduction in overbite in subjects who had a thicker masseter muscle before treatment with a BB. If the sample had been larger, this tendency may have been statistically significant. This finding needs confirmation with further investigations.

\section{CONCLUSIONS}

Treatment with removable posterior BBs in dolichofacial growing patients can influence the development of the masseter muscles, perhaps due to the stretching effect of the muscles as a BB of 5-mm thickness violated the freeway space. Masseter muscle thickness decreased, caused by a reduction in masticatory function during $\mathrm{BB}$ treatment. This therapy produced anterior rotation of the mandible with reduction of facial skeletal divergence.

\section{REFERENCES}

1. Woodside DG, Linder-Aronson S. Progressive increase in lower anterior face height and the use of posterior occlusal bite-block in its management. In: Graber LW, editor. Orthodontics. State of the art: essence of the science. St Louis: C. V. Mosby; 1986. p. 200-21.

2. Iscan HN, Sarisoy L. Comparison of the effects of passive posterior bite-blocks with different construction bites on the craniofacial and dentoalveolar structures. Am J Orthod Dentofacial Orthop 1997;112:171-8.

3. Akkaya S, Haydar S, Bilir E. Effects of spring-loaded posterior biteblock appliance on masticatory muscles. Am J Orthod Dentofacial Orthop 2000;118:179-83.

4. Mavropoulos A, Bresin A, Kiliaridis S. Morphometric analysis of the mandible in growing rats with different masticatory functional demands: adaptation to an upper posterior bite block. Eur J Oral Sci 2004;112:259-66. 
5. Bresin A, Kiliaridis S. Dento-skeletal adaptation after bite-raising in growing rats with different masticatory muscle capacities. Eur J Orthod 2002;24:223-37.

6. Ingervall B, Bitsanis E. A pilot study of the effect of masticatory muscle training on facial growth in long-face children. Eur J Orthod 1989;11:298-308.

7. Kiliaridis S, Engstrom C, Thilander B. The relationship between masticatory function and craniofacial morphology: a cephalometric longitudinal analysis in the growing rat fed a soft diet. Eur J Orthod 1985;7:273-83.

8. Lione R, Franchi L, Noviello A, Bollero P, Fanucci E, Cozza P. Three-dimensional evaluation of masseter muscle in different vertical facial patterns: a cross-sectional study in growing children. Ultrason lmaging 2013;35:307-17.

9. Ueda HM, Miyamoto K, Saifuddin M, 1shizuka Y, Tanne K. Masticatory muscle activity in children and adults with different facial types. Am J Orthod Dentofacial Orthop 2000;118:63-8.

10. Van Spronsen PH, Weijs WA, Valk J, Prahl-Andersen B, van Ginkel FC. Relationships between jaw muscle cross sections and craniofacial morphology in normal adults, studied with magnetic resonance imaging. Eur J Orthod 1991;13:351-61.

11. Satiroglu F, Arun T, lsik F. Comparative data on facial morphology and muscle thickness using ultrasonography. Eur J Orthod 2005; 27:562-7.

12. Charalampidou M, Kjellberg H, Georgiakaki 1, Kiliaridis S. Masseter muscle thickness and mechanical advantage in relation to vertical craniofacial morphology in children. Acta Odontol Scand 2008;66: 23-30.

13. Eckardt L, Harzer W. Computer tomographic volume registration of jaw and tongue muscles in consideration of relationship between function of muscles and skeletal configuration. Eur J Orthod 1993;15:442-9.

14. Antonarakis GS, Kiliaridis S. Predictive value of masseter muscle thickness and bite force on Class 11 functional appliance treatment: a prospective controlled study. Eur J Orthod 2015;37:570-7.

15. Farronato G, Giannini L, Galbiati G, Grillo E, Maspero C. Occlusoo-Guide versus Andresen activator appliance: neuromuscular evaluation. Prog Orthod 2013;14:4.

16. Turker KS. Electromyography: some methodological problems and issues. Phys Ther 1993;73:698-710.

17. Kiliaridis S, Kalebo P. Masseter muscle thickness measured by ultrasonography and its relation to facial morphology. J Dent Res 1991;70:1262-5.

18. Baccetti T, Franchi L, McNamara JA. The cervical vertebrae maturation (CVM) method for the assessment of optimal treatment timing in dentofacial orthopedics. Semin Orthod 2005;11: 119-29.

19. Tollaro 1, Baccetti T, Franchi L, Tanasescu CD. Role of posterior transverse interarch discrepancy in Class 11, Division 1 malocclusion during the mixed dentition phase. Am J Orthod Dentofacial Orthop 1996;110:417-22.

20. Riolo ML, Moyers RE, McNamara JA Jr, Hunter WS. An atlas of craniofacial growth: cephalometric standards from the University School Growth Study. Monograph 2. Craniofacial Growth Series.
Ann Arbor: Center for Human Growth and Development; University of Michigan; 1974. p. 37.

21. Cozza P, Giancotti A, Petrosino A. Butterfly expander for use in the mixed dentition. J Clin Orthod 1999;33:583-7.

22. Cozza P, Baccetti T, Mucedero M, Pavoni C, Franchi L. Treatment and posttreatment effects of a facial mask combined with a biteblock appliance in Class 111 malocclusion. Am J Orthod Dentofacial Orthop 2010;138:300-10.

23. Slakter MJ, Albino JE, Fox RN, Lewis EA. Reliability and stability of the orthodontic patient cooperation scale. Am J Orthod 1980;78: 559-63.

24. Raadsheer MC, Van Eijden TM, Van Sprosen PH, Van Ginkel FC, Kiliaridis S, Prahl-Andersen B. A comparison of human masseter muscle thickness measured by ultrasonography and magnetic resonance imaging. Arch Oral Biol 1994;39:1079-84.

25. Springate SD. The effect of sample size and bias on the reliability of estimates of error: a comparative study of Dahlberg's formula. Eur J Orthod 2012;34:158-63.

26. Hinton RJ. Jaw protuder muscles and condylar cartilage growth in the rat. Am J Orthod Dentofacial Orthop 1991;100:436-42.

27. Weiss WA, Hillen B. Correlation between the cross-sectional area of the jaw muscle and craniofacial size and shape. Am J Phys Anthropol 1986;70:423-31.

28. Kiliaridis S, Mills CM, Antonarakis GS. Masseter muscle thickness as a predictive variable in treatment outcome of the twin-block appliance and masseteric thickness changes during treatment. Orthod Craniofac Res 2010;13:203-13.

29. Serra MD, Duarte Gaviao MB, dos Santos Uchoa MN. The use of ultrasound in the investigation of the muscle of mastication. Ultrasound Med Biol 2008;34:1875-84.

30. Papageorgiou SN, Koretsi V, Jager A. Bias from historical control groups used in orthodontic research: a meta-epidemiological study. Eur J Orthod 2017;39:98-105.

31. Foot R, Dalci O, Gonzales C, Tarraf NE, Darendeliler MA. The shortterm skeleto-dental effects of a new spring for the intrusion of maxillary posterior teeth in open bite patients. Prog Orthod 2014;15:56.

32. Stavridi R, Ahlgren J. Muscle response to the oral-screen activator. An EMG study of the masseter, buccinator, and mentalis muscles. Eur J Orthod 1992;14:339-49.

33. Raadsheer MC, Kiliaridis S, van Eijden TM, van Ginkel FC, PrahlAndersen B. Masseter muscle thickness in growing individuals and its relationship to facial morphology. Arch Oral Biol 1996; 41:323-32.

34. Radsheed SA, Prabhu NT, Munshi AK. Electromyographic and ultrasonographic observations of masseter and anterior temporalis muscles in children. J Clin Pediatr Dent 1996;20:127-32.

35. Freeland TD. Muscle function during treatment with the functional regulator. Angle Orthod 1979;49:247-58.

36. Kuster R, Ingervall B. The effect of treatment of skeletal open bite with two types of bite-blocks. Eur J Orthod 1992;14:489-99.

37. de Almeida MR, Henriques JF, de Almeida RR, Weber U, McNamara JA Jr. Short-term effects produced by the Herbst appliance in the mixed dentition. Angle Orthod 2005;75:540-7. 